\title{
Genome-Wide Transcriptional Profile Analysis of Prunus persica in Response to Low Sink Demand after Fruit Removal
}

OPEN ACCESS

Edited by:

Pingfang Yang,

Wuhan Botanical Garden, China

Reviewed by:

Ji-Hong Liu,

Huazhong Agricultural University,

China

Nianjun Teng,

Nanjing Agricultural University, China

${ }^{*}$ Correspondence:

Shaohua Li

Shhli@ibcas.ac.cn

Specialty section:

This article was submitted to

Plant Proteomics,

a section of the journal

Frontiers in Plant Science

Received: 07 January 2016

Accepted: 06 June 2016

Published: 22 June 2016

Citation:

Duan W, Xu H, Liu G, Fan P, Liang Z and Li S (2016) Genome-Wide

Transcriptional Profile Analysis of Prunus persica in Response to Low

Sink Demand after Fruit Removal.

Front. Plant Sci. 7:883

doi: 10.3389/fpls.2016.00883

\author{
Wei Duan, Hongguo Xu, Guotian Liu, Peige Fan, Zhenchang Liang and Shaohua Li *
}

Beijing Key Laboratory of Grape Science and Enology and Key Laboratory of Plant Resources, Institute of Botany, The Chinese Academy of Sciences, Beijing, China

Prunus persica fruits were removed from 1-year-old shoots to analysis photosynthesis, chlorophyll fluorescence and genes changes in leaves to low sink demand caused by fruit removal (-fruit) during the final stage of rapid fruit growth. A decline in net photosynthesis rate was observed, accompanied with a decrease in stomatal conductance. The intercellular $\mathrm{CO}_{2}$ concentrations and leaf temperature increased as compared with a normal fruit load (+fruit). Moreover, low sink demand significantly inhibited the donor side and the reaction center of photosystem II. 382 genes in leaf with an absolute fold change $\geq 1$ change in expression level, representing 116 up- and 266 down-regulated genes except for unknown transcripts. Among these, 25 genes for photosynthesis were down-regulated, 69 stress and 19 redox related genes up-regulated under the low sink demand. These studies revealed high leaf temperature may result in a decline of net photosynthesis rate through down-regulation in photosynthetic related genes and up-regulation in redox and stress related genes, especially heat shock proteins genes. The complex changes in genes at the transcriptional level under low sink demand provided useful starting points for in-depth analyses of source-sink relationship in P. persica.

\section{Keywords: peach, low sink demand, photosynthesis, transcriptional profile, fruit removal}

\section{INTRODUCTION}

Photosynthesis is the basis of plant growth and development, and it plays a decisive role in crop yield and quality. The fruit is the most important sink organ for most horticultural plants. The presence or absence of the fruits has a significant effect on source leaf photosynthesis in many plant species including peach (Duan et al., 2008). Therefore, fruit removal has often been used to change the sink-source relationship in order to study photosynthetic responses under low sink demand.

Abbreviations: CAT, catalase; $C_{\mathrm{i}}$, Intercellular $\mathrm{CO}_{2}$ concentrations; DEGs, Differentially expressed genes; $E$, Transpiration rate; ESTs, Expressed sequence tags; FBPase, Fructose-1,6-bisphosphatase; GAPB, Glyceraldehyde-3-phosphate dehydrogenase B; GAPDH, Glyceraldehyde-3-phosphate dehydrogenase; $g_{s}$, Stomatal conductance; Hsp, Heat shock proteins; LHC, Light-harvesting complex; NDH, NAD(P)H dehydrogenase; OEC, oxygen-evolving complex; PAR, Photosynthetically active radiation; $P_{\mathrm{n}}$, Net photosynthesis rate; PQ, Plastoquinone; PSI, photosystem I; PSII, Photosystem II; RCA, Rubisco activase; ROS, reactive oxygen species; SBPase, Seduheptulose bisphosphatase; sHsps, small Hsps; $T_{\text {leaf }}$, Leaf temperature; TPI, triose-phosphate isomerase; TPM, Tags per million clean tags. 
Leaf net photosynthesis rate $\left(P_{\mathrm{n}}\right)$ was found to be reduced when the sink demand was lowered by removing fruits or flowers in herbaceous species such as potato (Basu et al., 1999), tomato (Walker and Ho, 1977), soybean (Setter et al., 1980), and Dahlia (Yan et al., 2011) as well as in woody plants such as grape (Downton et al., 1987), kiwifruit (Buwalda and Smith, 1990), apple (Gucci et al., 1995; Fan et al., 2010), citrus (Iglesias et al., 2002), coffee (DaMatta et al., 2008), peach (Li et al., 2005; Duan et al., 2008), and pine (López et al., 2015). A lot of studies support the hypothesis of end-product inhibition of photosynthesis to explain the response of the decline of $P_{\mathrm{n}}$ under the low sink demand (Paul and Foyer, 2001; Iglesias et al., 2002; Zhou and Quebedeaux, 2003; Wu et al., 2008). However, this conclusion is controversial (Li et al., 2007; DaMatta et al., 2008). In our previous work it was found that low sink demand increased leaf temperature (Li et al., 2001, 2005, 2007; Duan et al., 2008; Cheng et al., 2009; Fan et al., 2010). So we speculated high leaf temperature might cause irreversible damage to photosynthetic apparatus when it was above the optimum temperature of photosynthesis. To date, the specific mechanism for the effect of low sink demand on photosynthesis is unclear.

In order to understand the molecular basis of change in source-sink response, gene expression profiling using expressed sequence tags or microarray were carried out in some plant species. For example, leaf shading treatment in $\mathrm{C}_{4}$ plants such as sugarcane resulted in the up-regulation of several genes associated with photosynthesis, mitochondrial metabolism, and sugar transport (McCormick et al., 2008). cDNA microarray analysis in sugarcane showed that elevated $\mathrm{CO}_{2}$ levels modify the expression of genes related to photosynthesis and development (De Souza et al., 2008). Moreover, severely defoliated plants of perennial ryegrass showed increased abundance of photosynthesis-related gene transcripts (Lee et al., 2011). Changes in gene expression due to sink removal in soybean leaves were monitored using an oligonucleotide microarray in combination with targeted metabolite profiling (Turner et al., 2012). However, the genes related to metabolism and the selected signature genes showed diverse profiles in the above mentioned studies. Therefore, there is a lack of systematic analysis of changes in leaf gene expression under the source-sink regulation.

In this study, we studied the changes in photosynthesis and chlorophyll fluorescence parameters in $P$. persica leaves under normal sink demand and low sink demand by fruit removal. Moreover, we performed deep sequencing analysis using the Solexa digital gene expression system to compare the differentially expressed genes in response to -fruit and + fruit. These sequencing datasets allowed us to comprehensively characterize the molecular basis of the physiological processes under low sink demand and gain insight for further research.

\section{MATERIALS AND METHODS}

\section{Plant Materials}

In this study, we used 4-year-old peach "Zaojiubao" (mutant of "Okubo") [Prunus persica (L.) Batch] trees, which have a midripening peach with fruit maturity occurring in the middle of
July. The trees were planted $2 \mathrm{~m}$ apart within rows and $5 \mathrm{~m}$ apart between rows. They were trained to " $Y$ " training systems and pruned using the long pruning method in winter (Li et al., 1994).

\section{Treatments}

During the final stage of rapid fruit growth (on 23 July 2010, about 85 days after full blossom), 1-year-old shoots located on the southwest and southeast sides of the tree in the outer part of the crown were used as the unit of sink-source manipulation. Those 1-year-old shoots with similar light exposure were selected according to their uniformity in length $(40-50 \mathrm{~cm})$ and growth status (at least one new shoot per 1-year-old shoot). Each selected 1-year-old shoot, which supported one fruit and one new shoot, was considered a plot. Eight mature leaves were retained on each new shoot by topping and removing the smaller basal leaves. Half of the shoots from the previous season had fruits while the fruit were removed from the other half after sunset on 23 July 2010. Moreover, the export of assimilates from the treated and untreated parts, including the base and top parts of the 1-year-old shoots, was strictly controlled by girdling of the 1-year-old shoots. Twenty one-year-old shoots per treatment were selected for measurements of gas exchange and chlorophyll fluorescence, and leaves were sampled from 12 one-year-old shoots per treatment for the gene analyses.

\section{Measurement of Photosynthetic Gas Exchange Parameters}

Photosynthetic gas exchange parameters including $P_{\mathrm{n}}$, stomatal conductance $\left(g_{\mathrm{s}}\right)$, and intercellular $\mathrm{CO}_{2}$ concentration $\left(C_{\mathrm{i}}\right)$ were measured using a Li-6400 portable photosynthesis system (LiCor Inc., Lincoln, NE, USA). The measurements were recorded between 0700 and $1800 \mathrm{~h}$, on 25 July 2010, the 2nd day after initiating the source-sink manipulation on five leaves from each of five 1-year-old shoots per treatment. Photosynthetically active radiation (PAR), $g_{s}$, transpiration rate $(E), C_{\mathrm{i}}$ and leaf temperature $\left(T_{\text {leaf }}\right)$ were obtained when $P_{\mathrm{n}}$ was measured.

\section{Chlorophyll a Fluorescence Kinetics Transient Analysis (OJIP-Test)}

The OJIP-test parameters were also measured on 25 July 2010, the same day as gas exchange measurement as Luo's methods (Luo et al., 2011). A Handy-Plant Efficiency Analyzer (Hansatech Instruments, King's Lynn, Norfolk, UK) was used for determine the fluorescence signals on the same leaves used for gas exchange measurements. The measurements were made after dark adaption for more than $15 \mathrm{~min}$. The transients were induced by red light of about $3000 \mu \mathrm{mol} \mathrm{m} \mathrm{m}^{-2} \mathrm{~s}^{-1}$ provided by an array of six light emitting diodes (peak wavelength $650 \mathrm{~nm}$ ). The fluorescence signals were recorded from $10 \mu \mathrm{s}$ to $1 \mathrm{~s}$ with a data acquisition rate of $10 \mu \mathrm{s}$ for the first $2 \mathrm{~ms}$ and every $1 \mathrm{~ms}$ thereafter. The following data from the original measurements were used: $F_{\mathrm{m}}$ : maximal fluorescence intensity; $F_{\mathrm{k}}$ : fluorescence intensity at $300 \mu \mathrm{s}$ [required for calculation of the initial slope $\left(M_{\mathrm{o}}\right)$ of the relative variable fluorescence $(\mathrm{V})$ kinetics and $\left.\mathrm{W}_{\mathrm{k}}\right] ; F_{\mathrm{j}}$ : the fluorescence intensity at $2 \mathrm{~ms}$ (the J-step), $F_{\mathrm{i}}$ : the fluorescence intensity at $30 \mathrm{~ms}$ (the I-step). The derived parameters were as follows: $F_{\mathrm{o}}$ : fluorescence intensity at $50 \mu \mathrm{s}$. The parameter $\mathrm{W}_{\mathrm{k}}$ 
on donor side of photosystem II (PSII), represents the damage to oxygen evolving complex (OEC), $\mathrm{W}_{\mathrm{k}}=\left(F_{\mathrm{k}}-F_{\mathrm{o}}\right) /\left(F_{\mathrm{j}}-\right.$ $F_{\mathrm{o}}$ ); the parameter $\mathrm{RC}_{\mathrm{QA}}$ on reaction center of PSII, represents the density of $\mathrm{Q}_{\mathrm{A}}$-reducing reaction centers, $\mathrm{RC}_{\mathrm{QA}}=\varphi_{\mathrm{Po}}$ $\times\left(V_{\mathrm{j}} / M_{\mathrm{o}}\right) \times(\mathrm{ABS} / \mathrm{CS})$; the parameter $\varphi_{P o}$ on acceptor side of PSII, represents the maximum quantum yield of primary photochemistry at $t=0, \varphi_{\mathrm{Po}}=T R \mathrm{To} / \mathrm{ABS}=1-F_{\mathrm{o}} / F_{\mathrm{m}}$; the parameter $\varphi_{\text {Eo }}$ on acceptor side of PSII, represents quantum yield for electron transport (at $t=0), \varphi_{\mathrm{Eo}}=E T_{\mathrm{o}} / \mathrm{ABS}=\left(F_{\mathrm{m}^{-}}\right.$ $\left.F_{\mathrm{j}}\right) / F_{\mathrm{m}}$; the parameter $\psi_{\text {Eo }}$ on acceptor side of PSII, represents the probability with which a trapped exciton moves an electron into the electron transport chain beyond $\mathrm{Q}_{\mathrm{A}}^{-}, \psi_{\mathrm{Eo}}=E T_{\mathrm{o}} / \mathrm{TRo}$ $=\left(F_{\mathrm{m}}-F_{\mathrm{j}}\right) /\left(F_{\mathrm{m}}-F_{\mathrm{o}}\right)$. The calculation and derivation of a range of new parameters from O-J-I-P transients is shown in Table S1. Five independent replicates were used in both treatments and controls respectively.

\section{Digital Expression Library Construction and Solexa Sequencing}

Leaves ware sampled at $1400 \mathrm{~h}$ on 25 July, the same day as gas exchange measurement. Total RNA was isolated from the pooled samples of three replicates with or without source-sink treatment, using plant total RNA isolation kit (Tiandz Inc.; Beijing, China). Gene Expression Sample Prep Kit (Illumina Inc.; San Diego, CA, USA) was used for sequence tag preparation according to the manufacturer's protocol. Six micrograms of total RNA were extracted and the mRNA was purified via Biotin-Oligo (dT) magnetic bead adsorption. First strand cDNA was synthesized with oligo (dT) on the bead. After secondstrand cDNA synthesis, double strand cDNA was digested with NlaIII endonuclease producing a bead-bound cDNA fragment containing sequence from the 39-most CATG to the polyA tail. These cDNA fragments were purified with magnetic bead precipitation and Illumina adapter 1(GEX adapter 1) was added to newly formed $5^{\prime}$ sticky end of cDNA fragments. The junction of GEX adapter 1 and CATG site was recognized by MmeI, which cuts $17 \mathrm{bp}$ downstream of the CATG site, producing $17 \mathrm{bp}$ cDNA sequence tags with GEX adapter 1 . The $3^{\prime}$ fragments were removed using magnetic bead precipitation; and the Illumina adapter 2 (GEX adapter 2) was ligated to the new $3^{\prime}$ end of the cDNA fragment, which represented the tag library.

The cDNA fragments with GEX adapters 1 and 2 were subject to 15 cycles of linear PCR amplification by Phusion polymerase (Finnzymes, Espoo, Finland). The resulting 85 base fragments were purified by $6 \%$ TBE PAGE Gel electrophoresis. After double strand denaturation, the single chain molecules were fixed onto the Solexa Sequencing Chip (flow cell). Each molecule grew into a cluster sequencing template through in situ amplification, which represented a single tag derived from a single transcript. The sequencing was by the Beijing Genomics Institute (BGI, www.genomics.org.cn) using an Illumina HiSeq 2000 System. Four color-labeled nucleotides were added during sequencing; and the produced $49 \mathrm{bp}$ sequences contained target tags and a $3^{\prime}$ adaptor. Base-calling was performed using the Illumina Pipeline. After purity filtering and initial quality tests, the reads were sorted and counted for the following analysis. The clean reads data of - fruit and + fruit used in this manuscript have been uploaded respectively to SRA database at NCBI (accession numbers: SAMN05178616 and SAMN05178617).

\section{Sequence Annotation}

"Clean Tags" were obtained by trimming adapter sequences and filtering adaptor-only tags and low-quality tags (containing ambiguous bases) using the Fastx-toolkit (http://hannonlab.cshl. edu/fastx_toolkit). Sequence alignment was done with Bowtie 0.12.8 using the Peach Genome database (http://www.rosaceae. org/species/prunus_persica/genome_v1.0). All clean tags were annotated based on transcript sequences of peach reference genes, masked peach genome sequences (excluding the repeating sequences), and NCBI. For conservative and precise annotation, only sequences with perfect homology or one nucleotide mismatch were considered for further annotation.

\section{Identification of Differentially Expressed Genes}

Numbers of annotated clean tags for each gene were calculated after alignment and then normalized to TPM (tags per million clean tags) (AC't Hoen et al., 2008; Morrissy et al., 2009). The genes that had $<10$ TPM in both + fruit and -fruit libraries were excluded first. The default value (tag number) of genes that not found in any of the libraries was one. Differentially expressed genes (DEGs) in -fruit as compared with + fruit were identified based on a rigorous algorithm (Audic and Claverie, 1997). Pvalue was used to test the authenticity of differential transcript accumulation (Audic and Claverie, 1997; Wu et al., 2010). In the $P$-value formula below, the total clean tag number of the + fruit library is noted as N1, and total clean tag number of -fruit library as N2; gene A holds $\mathrm{x}$ tags in +fruit and y tags in -fruit library. The probability of gene A expressed equally between two samples can be calculated with:

$$
P(y \mid x)=\left(\frac{N 2}{N 1}\right)^{y} \frac{(x+y) !}{x ! y !\left(1+\frac{N_{2}}{N_{1}}\right)^{(x+y+1)}}
$$

The Bonferroni corrected $P$-value was applied to control the false discovery rate (FDR) in the multiple comparison and analysis during the identification of DEGs (Benjamini et al., 2001). An :FDR $<0.001$ and the absolute value of $\log _{2}$ ratio $\geq 1$ " was used as the threshold to determine the significance of gene expression differences. The differently expressed genes were categorized into functional groups and mapped using Mapman (version 3.5.1R2) according to the standard protocol (Usadel et al., 2009).

\section{Real-Time PCR Analysis}

Total RNA was isolated using the same method as used for DGE analysis. Real-time PCR was carried out using three independent biological replicates each containing three technical replicates. First-strand cDNA was synthesized using Oligo $(\mathrm{dT})_{15}$ (Sigma, Hamburg, Germany) and Superscript III Reverse Transcriptase (Invitrogen, Carlsbad, CA, USA). cDNAs were diluted 20 fold for use as template. Specific primer pairs of 10 transcripts were designed using Primer3 (v. 0.4.0; http:// frodo.wi.mit.edu/) and shown in Table S2. Experiments were carried out using FastStart Universal SYBR Green Master 
(Roche Diagnostics, Mannheim, Germany) with SteopOneplus ${ }^{\mathrm{TM}}$ Real-Time PCR system (Applied Biosystems). Data were analyzed using qbase ${ }^{\text {PLUS }}$ software (http://www.biogazelle.com/ products). Transcript levels were normalized against the peach reference glyceraldehyde-3-phosphate dehydrogenase (GAPDH) gene (ppa006087m; Forward primer: 5-GAAATTCGATTTGCA TGAGC-3, Reverse primer: 5-CAATGCCATTCAAGCTAAGG3) according to Tong et al. (2009). The fold change in mRNA expression was estimated using threshold cycles, by the $\triangle \triangle \mathrm{CT}$ method.

\section{RESULTS}

\section{Diurnal Variations of Photosynthetic Parameters}

Low sink demand had significant effects on the diurnal variations in $P_{\mathrm{n}}, g_{\mathrm{s}}, C_{\mathrm{i}}, E$, and $T_{\text {leaf }}$ (Figure 1 ) on the 2 nd day after removing fruit. Values of $P_{\mathrm{n}}, g_{\mathrm{s}}$, and $E$ were gradually increased until
$1100 \mathrm{~h}$ reached maximum when PAR about $1000 \mu \mathrm{mol} \mathrm{m}^{-2} \mathrm{~s}^{-1}$, thereafter $P_{\mathrm{n}}, g_{\mathrm{s}}$, and $E$ decreased slowly as PAR increased in + fruit shoots. The - fruit treatment significantly reduced $P_{\mathrm{n}}, g_{\mathrm{s}}$, and $E$ throughout most of the day compared with the + fruit treatment (Figures 1A,B,D). At $1300 \mathrm{~h}$, values of $P_{\mathrm{n}}, g_{\mathrm{s}}$, and $E$ of - fruit were only $2.13,11.05$, and $1.38 \%$ of + fruit values respectively. $P_{\mathrm{n}}$ and $g_{\mathrm{s}}$ decreased to almost zero between $1000 \mathrm{~h}$ and $1400 \mathrm{~h}$. Trends in $T_{\text {leaf }}$ (Figure 1E) were similar to those in PAR. $T_{\text {leaf }}$ reached the maximum $\left(42.19^{\circ} \mathrm{C}\right)$ when PAR was about $1100 \mu \mathrm{mol} \mathrm{m} \mathrm{m}^{-2} \mathrm{~s}^{-1}$ at $1400 \mathrm{~h}$. Throughout most of the day $T_{\text {leaf }}$ values in leaves of - fruit shoots were significantly higher than in leaves of + fruit shoots (Figure 1E). The pattern of diurnal change in $C_{\mathrm{i}}$, differed between the + fruit and - fruit treatments (Figure 1C). Maximal $C_{\mathrm{i}}$ occurred just after sunrise then decreased gradually in leaves in both treatments. Values of $C_{\mathrm{i}}$ decreased until the lowest value at $1100 \mathrm{~h}$, and began to recover at $1600 \mathrm{~h}$ in the afternoon in +fruit, whereas it increased sharply at $0900 \mathrm{~h}$, and high $C_{\mathrm{i}}$ was maintained between $1000 \mathrm{~h}$ to $1400 \mathrm{~h}$

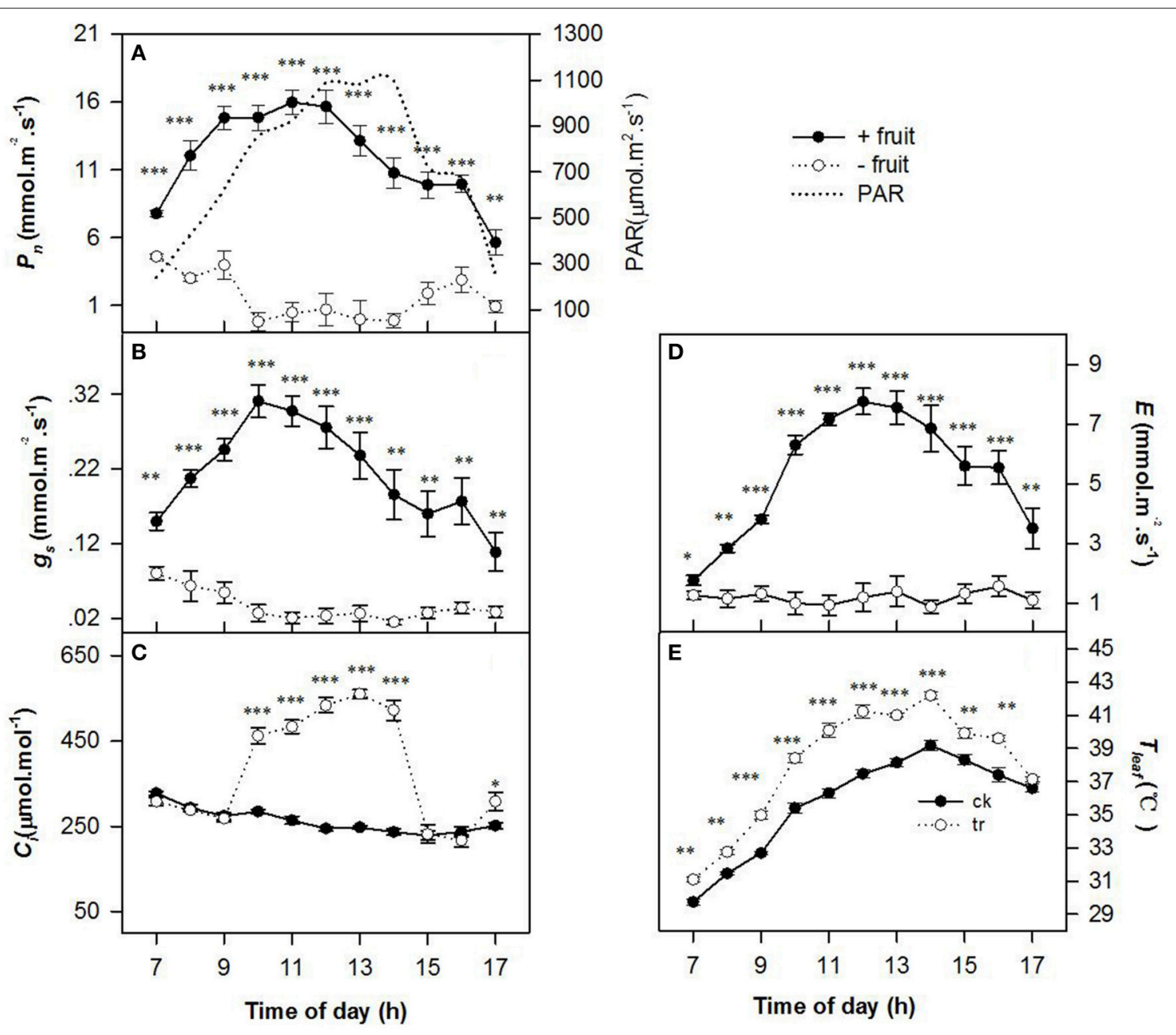

FIGURE 1 | Diurnal variation in gas exchange parameters, including net photosynthesis rate $\left(\boldsymbol{P}_{\mathrm{n}}\right)(\mathrm{A})$, stomatal conductance $\left(g_{\mathrm{s}}\right)(\mathrm{B})$, intercellular $\mathrm{CO} \mathbf{2}_{2}$ concentration $\left(C_{i}\right)(C)$, transpiration rate $(E)(D)$, and leaf temperature $\left(T_{\text {leaf }}\right)(E)$ in peach source leaves in response to low sink demand on the 2 nd day after removing fruit. The time course of PAR is given in (A). Each value represents the mean $\pm S E$ of five replicates. The asterisks *, ${ }^{* *}$, and *** indicate significant differences between - fruit and +fruit at $P<0.05,0.01$, and 0.001 , respectively. 
in -fruit. Moreover, significantly higher $C_{\mathrm{i}}$ values were obtained in -fruit than in +fruit from 1000 until $1400 \mathrm{~h}$.

\section{Diurnal Variations of Chl Fluorescence Parameters}

We further investigated the relationship between $P_{\mathrm{n}}$ decline and electron transport chain of PSII under the low demand by chlorophyll $a$ fluorescence kinetics transient (OJIP-test). Wk had similar diurnal variation patterns in both - fruit and + fruit (Figure 2A). In the morning $\mathrm{Wk}$ increased progressively up to about $1300 \mathrm{~h}$, and then they decreased. Parameters $\mathrm{RC}_{\mathrm{QA}}, \varphi_{\mathrm{Po}}$, $\varphi_{\text {Eo }}, \psi_{\text {Eo }}$, and $\delta_{\text {Ro }}$ remained relatively stable throughout the day in + fruit plants, however they were at a maximum at $0700 \mathrm{~h}$, then decreased progressively up to about mid-day, and remained at a low level in the afternoon (Figures 2B-E) except $\delta_{\text {Ro }}$ in -fruit plants. Low sink demand resulted in $\mathrm{RC}_{\mathrm{QA}}, \varphi_{\mathrm{Po}}, \varphi_{\mathrm{Eo}}, \psi_{\mathrm{Eo}}$ about $24,13,16,11 \%$ lower values, and $\mathrm{W}_{\mathrm{k}}$ about $8 \%$ higher than
+ fruit at $1300 \mathrm{~h}$ respectively. Parameter $\delta_{\text {Ro }}$ signifies the redox state of photosystem I (PSI). However there was not significant differences in $\delta_{\text {Ro }}$ between - fruit and + fruit although lower in the beginning and the end of day and higher values around noon were observed in -fruit than in +fruit (Figure 2F).

\section{Digital Expression Libraries Construction and Tag Sequencing}

Unique tags that perfectly matched reference genes in each library were normalized to tags per million clean tags (TPM) and used to evaluate the expression level of transcripts. The transcripts detected with at least two-fold differences in the two libraries are shown in Figure 3 (FDR $<0.001$ ). The details of DEGs, including original TPM, fold-change, annotation, $P$ value and FDR in both materials are shown in Table S3.

The distribution of unique tags with different copy numbers (clean tags) in +fruit and -fruit libraries were counted

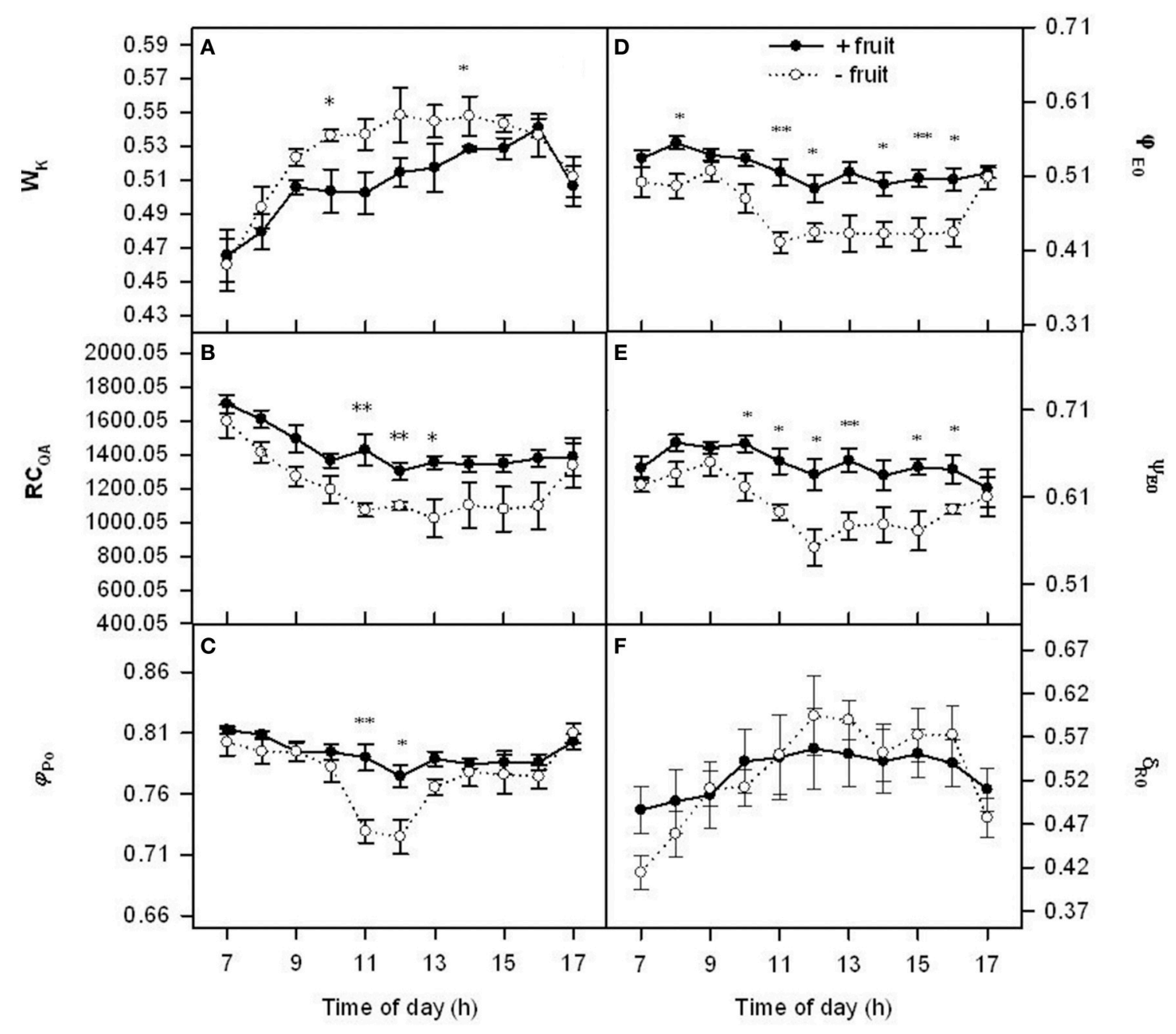

FIGURE 2 | Diurnal variations in donor side (Wk), reaction center (RC $\mathbf{Q A}_{\mathrm{QA}}$ ), acceptor side $\left(\varphi_{\mathrm{Po}}, \varphi_{\text {Eo }}, \psi_{\text {Eo }}\right)$ (A-E) parameters of PSII and $\delta_{\mathrm{Ro}}$ (the efficiency with an electron can move from plastoquinone (PQ) through PSII to the PSI end electron acceptor) (F) in peach source leaves in response to low sink demand on the 2 nd day after removing fruit. Each value represents the mean \pm S.E. of five replicates. The asterisks ${ }^{*}$, ${ }^{* *}$, and ${ }^{* *}$ indicate significant differences between -fruit and +fruit at $P<0.05,0.01$, and 0.001, respectively. The detailed meanings of $\mathrm{W}_{\mathrm{k}}, \mathrm{RC}_{\mathrm{QA}}, \varphi_{\mathrm{PO}_{\mathrm{O}}}, \psi_{\mathrm{EO}}, \varphi_{\mathrm{EO}}$, and $\delta_{\mathrm{Ro}}$ were shown in Table $\mathbf{S} 1$. 
(Table 1). A total of $6,039,500$ and 5,857,099 raw tags were sequenced in +fruit and -fruit libraries, including 247,102 and 243,331 distinct tags, respectively. Low quality tags and virus contaminations were filtered, and single-copy tags were excluded after which 118,192 and 104,826 distinct tags were obtained in each library. The majority of clean tags (about $82 \%$ from each library) were present in low copy numbers ( $<10$ copies), and $\sim 10 \%$ tags from each library were counted between 11 and 100 times. Approximately, 3.3\% tags were detected more than a 100 times.

\section{Analysis of Tag Mapping}

The sequencing saturation was analyzed in the two libraries based on the number of identified genes to estimate whether the sequencing depth was sufficient for the transcriptome coverage. The number of tags reached saturation when no new genes were detected (Figure S1). All samples reached a plateau shortly after four million tags or higher were sequenced in both + fruit and -fruit libraries. No new genes were identified as the tag number approached six million in both libraries indicating that the capacity of the two libraries had approached saturation.

To identify the genes corresponding to 118,192 and 104,826 meaningful tags in each library, an essential dataset containing 286,689 reference genes expressed in the peach genome from http://www.rosaceae.org/node/355 was used. Altogether, 270,059 genes $(94.32 \%)$ have the CATG sites, resulting in a total number of 147,813 unambiguous reference tags. By assigning the experimental Solexa tags to the virtual reference ones (Table S4), we observed that 44,173(37.4\%) and 37, 007 (35.3\%) tags were perfectly matched to + fruit and -fruit libraries respectively for the reference genes. Moreover, $\sim 18 \%$ tags in the two libraries were mapped to the antisense strands suggesting that those regions might be directionally transcribed.

Altogether, there were 52,347 (44.3\%) tags in the +fruit library and $43,863(41.8 \%)$ tags in the -fruit library were found to match the annotated reference genes. The unmatched tags were then blasted against the peach genome, and $\sim 40 \%$ tags were matched to the genomic sequences in the two libraries. As a result of the significant sequencing depth of Solexa technology and incomplete annotation of the peach genome. However, there were 19.3 and $17.8 \%$ unmatched tags in each library as result of the significant sequencing depth of Solexa technology and incomplete annotation of the peach genome.

\section{Function Categories of Differentially Expressed Genes}

The functional classification of DEGs was further examined in peach to investigate the pattern of transcriptome regulation that
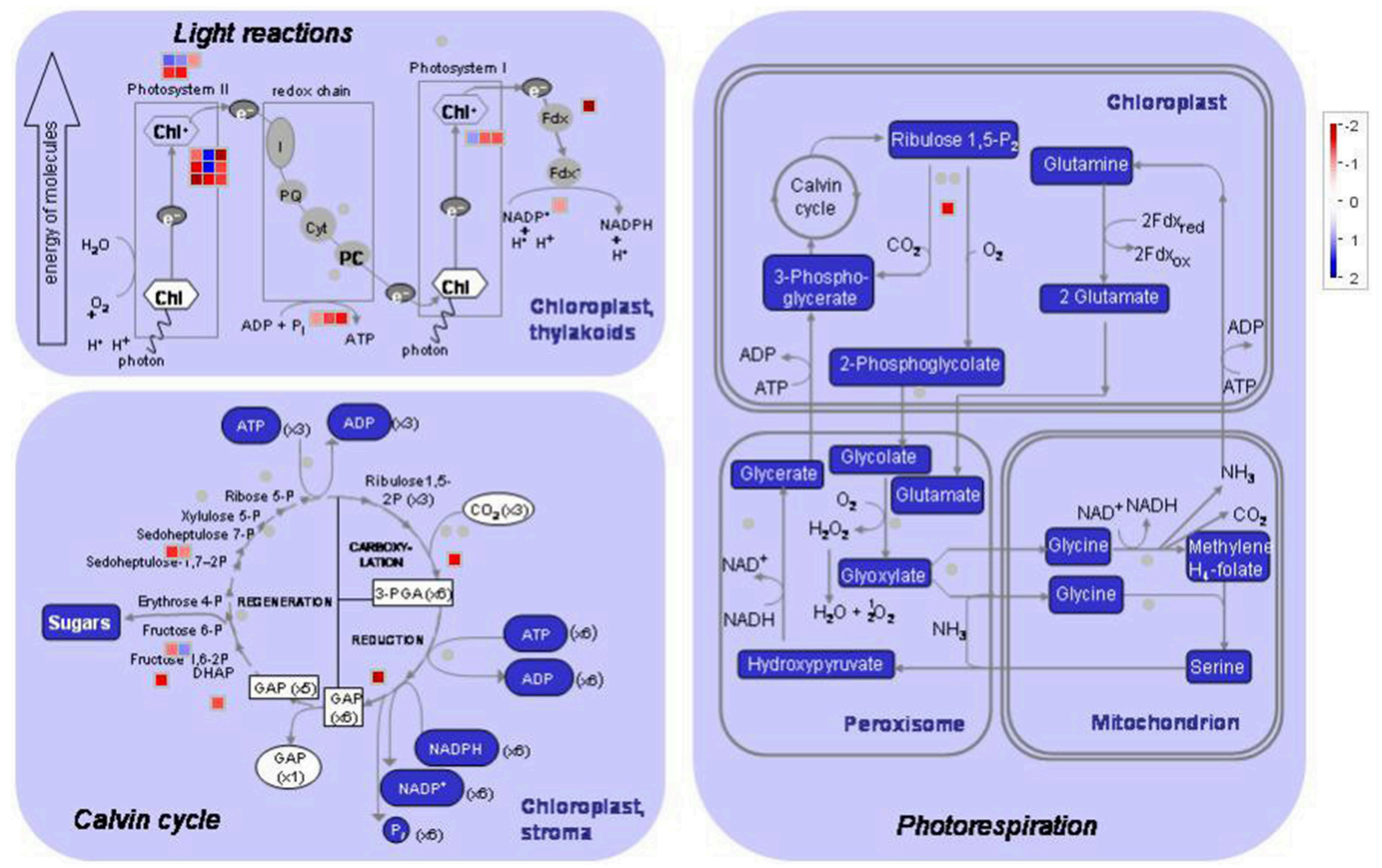

FIGURE 3 | MapMan visualization of photosynthesis in peach leaves under low sink demand. Each square corresponds to a gene that is differentially regulated. Red indicates significant up-regulation while blue indicates down-regulation under low sink treatment. Only the genes that were significantly differentially expressed are represented in the MAPMAN figure. 
TABLE 1 | Distribution of the sequenced tags from libraries of peach leaves under normal sink demand (+fruit) or low sink demand (-fruit).

\begin{tabular}{lcc}
\hline & +fruit & -fruit \\
\hline Total tags & $6,039,500$ & $5,857,099$ \\
Clean tags & $5,902,114$ & $5,709,974$ \\
Total number of distinct tags & 247,102 & 243,331 \\
Unique tag & 118,192 & 104,826 \\
Tag copy muber $<2$ (clean tag) & $121,198(49.05 \%)$ & $130,727(53.72 \%)$ \\
$2-5$ & $67,343(27.25 \%)$ & $57,105(23.47 \%)$ \\
$6-10$ & $15,889(6.43 \%)$ & $14,452(5.93 \%)$ \\
$11-20$ & $11,000(4.45 \%)$ & $10,247(4.21 \%)$ \\
$21-50$ & $10,093(4.08 \%)$ & $9697(3.99 \%)$ \\
$51-100$ & $5514(2.23 \%)$ & $5315(2.18 \%)$ \\
$>100$ & $8353(3.38 \%)$ & $8010(3.29 \%)$ \\
\hline
\end{tabular}

occurred under the low sink demand. These genes were found to cover a lot of functions by using MapMan functional categories. Thereafter, the 1765 differently expressed proteins were classified into functional categories with the exception of 554 genes that were not assigned to any groups (Figure 4). The main categories included protein (16.4\%), RNA (10.5\%), and transport (5.4\%). Miscellaneous enzyme families, signaling, stress, cell, hormone metabolism, development, and photosynthesis categories each accounted for $2.0-5.0 \%$ of the DEGs. Each of the other categories accounted for $<2 \%$ of DEGs. Full datasets are available online in Table S3. The photosynthesis related genes were regulated by source-sink relationship treatment.

As regards genes related to photosynthesis, a total of 25 genes were down-regulated under low sink demand (Table 2, Figure 3). 17 genes were involved in the light reaction. Among these groups, one oxygen-evolving complex-related gene was severely inhibited. The expression levels of LHCB3 and LHCA2 were inhibited under low sink demand. However, the expression of LHCB6 and LHC2.1 increased in the expression of genes. The $\mathrm{PsaO}$ subunit of PSI is declined under low sink demand. PPL2 (PsbP-like protein 2), PsbP, PsbY, and thylakoid lumenal $19 \mathrm{kDa}$ protein were repressed while PsbR increased under low sink demand. In the Calvin cycle, seven genes included seduheptulose bisphosphatase (SBPase), fructose-1,6-bisphosphatase (FBPase), aldolase, triose-phosphate isomerase (TPI), glyceraldehyde-3phosphate dehydrogenase B subunit (GAPB), and Rubisco activase (RCA) were severely repressed. Only RCA was downregulated in photorespiration.

\section{Confirmation of DEGs by Real-Time PCR Analysis}

Ten candidate genes that showed change in the pattern of expression in response to low sink demand were randomly selected from the peach DEGs for Real-time PCR analysis. Among them, six genes were up-regulated and four genes were down-regulated. The list of the genes and the comparison of fold changes between deep sequencing and Real-time PCR in + fruit and -fruit were shown in Table S5. The primers used for Real-time PCR of the selected genes are listed in Table S2. The
Real-time PCR based expression patterns of all 10 selected genes showed a trend similar to that detected by the Solexa-sequencing method, which confirmed the reliability of our transcriptome analysis (Table S5).

\section{DISCUSSION}

Leaf transpiration and temperature play an important role on the source-sink relationship. Low sink demand by removing fruit or tuberous root sink resulted in significantly decreased $g_{\mathrm{s}}$ but increased $T_{\text {leaf }}$ in higher plants (DaMatta et al., 2008; Duan et al., 2008; Wu et al., 2008; Fan et al., 2010; Yan et al., 2011). So Li et al. (2001) suggested that the decreased $g_{\mathrm{s}}$ may be considered as the trigger or promoter and increased $T_{\text {leaf }}$ as the actor for regulating photosynthesis under a lower sink-source ratio. Low sink by fruit removal resulted in a decreased $P_{\mathrm{n}}$ with lower $g_{\mathrm{s}}$ and higher $T_{\text {leaf }}$ in this study (Figure 1), which corroborates the results of previous studies in peaches or in other higher plants (Li et al., 2005; Fan et al., 2010; Yan et al., 2013). Moreover, significantly higher $C_{\mathrm{i}}$ was observed in -fruit than in +fruit (Figure 1C). In general, leaf $C_{\mathrm{i}}$ increases with a decrease in $g_{\mathrm{s}}$ and $P_{\mathrm{n}}$ when there is non-stomatal limitation in higher plant (Farquhar and Sharkey, 1982). Thus, the lower $P_{\mathrm{n}}$ under low sink demand in -fruit in this study was primarily due to non-stomatal limitation.

In OJIP-test, $\mathrm{RC}_{\mathrm{QA}}$ shows the density of the of $\mathrm{Q}_{\mathrm{A}}$-reducing PSII reaction centers. $\mathrm{W}_{\mathrm{k}}$ is used as a specific indicator of damage to PSII donor side (Strasser, 1997), while $\varphi$ Po , $\varphi$ Eo, and $\psi$ Eo represent the acceptor side parameters of PSII. Low sink demand mainly resulted in a decrease in the acceptor side parameters $\varphi$ Po and $\psi$ Eo of PSII and PSII reaction centers parameters $\mathrm{RC}_{\mathrm{QA}}$ (Figure 2). These results in the present study were similar to the results obtained on bean at late stages after the removal of the sink of roots and pods plants (Yan et al., 2013). The $P_{\mathrm{n}}$ reduction could be attributed to essentially the probability that a trapped exciton moves an electron into the electron transport chain beyond $\mathrm{Q}_{\mathrm{A}}^{-}$ and $\varphi$ Po (Xiang et al., 2013).

Photosynthesis is one of the most heat sensitive processes and it can be completely inhibited by high temperature before other symptoms of the stress are detected (Berry and Bjôrkman, 1980). In this study 31 genes involved in the light reaction, Calvin cycle and photorespiration were down-regulated under low sink demand (Table 2, Figure 3). These changes in photosynthesisrelated genes were similar to those observed in the application of a cold-girdle to $\mathrm{C}_{4}$ sugarcane (McCormick et al., 2008). Linear electron flow involves light-stimulated electron transfer between PSII and PSI, which stores the majority of photosynthetic energy. A total of 17 genes related to electron transfer were significantly down-regulated (Table 2), suggesting that the light reaction might be repressed by low sink demand. The repression electron transport causes the production of significant reactive oxygen species (ROS) early in the low sink response resulting in the inhibition of plant photosynthesis (Duan et al., 2008).

The light-harvesting complex (LHC) functions as a light receptor, and captures and delivers excitation energy to photosystems. LHCB3 serves as an intermediary in light energy transfer from the main LHCB1/LHCB2 antenna to the core 
of PSII (Standfuss and Kühlbrandt, 2004). In this study, the expression levels of LHCB7, LHCB3, and LHCA2 were inhibited under low sink demand. However, the expression of LHCB6 and LHC2.1 increased, indicating that they may be stable under low sink demand. The PsaO subunit of PSI is involved in balancing the excitation pressure between the two photosystems. Consistent with this observation, the levels of PsaE-2 and PsaO declined under low sink demand (Table 2).

PsbP $(23 \mathrm{kD})$ is one of three extrinsic nuclear-encoded subunits of eukaryotic PSII oxygen-evolving complex (OEC). PsbR $(10 \mathrm{kD})$ protein found in plant PSII plays a role in water oxidation (Roose et al., 2007). PsbY is one of the low molecular mass subunits of oxygen-evolving PSII (Kawakami et al., 2007). A PsbP-like protein 2 was previously shown to be essential for the accumulation of the chloroplast $\mathrm{NAD}(\mathrm{P}) \mathrm{H}$ dehydrogenase (NDH) complex (Ishihara et al., 2007). In the present study, PPL2 (PsbP-like protein 2), PsbP, PsbY, and thylakoid lumenal $19 \mathrm{kDa}$ protein were repressed while PsbR increased under low sink demand. Moreover, the chlorophyll fluorescence parameter $\mathrm{W}_{k}$ also showed that the OEC of PSII was damaged under low sink demand.

In the Calvin cycle, seven genes (SBPase, FBPase, TPI, GAPB, RCA) were severely repressed involved in the reduction, regeneration, and carboxylation (Table 2). The repression of these genes suggested that these processes were negatively regulated by low sink demand. Only one gene was downregulated in photorespiration indicating that most genes involved in photorespiration are not responsive to low sink demand. Arabidopsis plants growing for long periods under high $\mathrm{CO}_{2}$ resulted in a significant decrease in $\mathrm{rbcL}$ and $\mathrm{rbcS}$ transcripts, which encode the large and small subunits of Rubisco, respectively (Cheng et al., 1998).

In this study, nine Hsps were up-regulated under the low sink demand (Table 3). Most of them were belonged to one of the three major classes of molecular chaperones, HSP90, HSP70, and sHSPs. Four sHsps were up-regulated in low sink demand compared to control. In plants, sHsps have been reported to be involved in protecting macromolecules like enzymes, lipids, nucleic acid, and mRNAs from dehydration (Yamaguchi-Shinozaki et al., 2002). sHSPs are the most abundant and diverse HSPs produced at high temperatures (Palmblad et al., 2008). Furthermore, some sHSPs are also known to be induced by various abiotic stresses such as cold, salinity, drought, and chemical pollution (Palmblad et al., 2008). Proteins from the HSP70 family are essential for preventing aggregation and assisting re-folding of non-native proteins under stressing

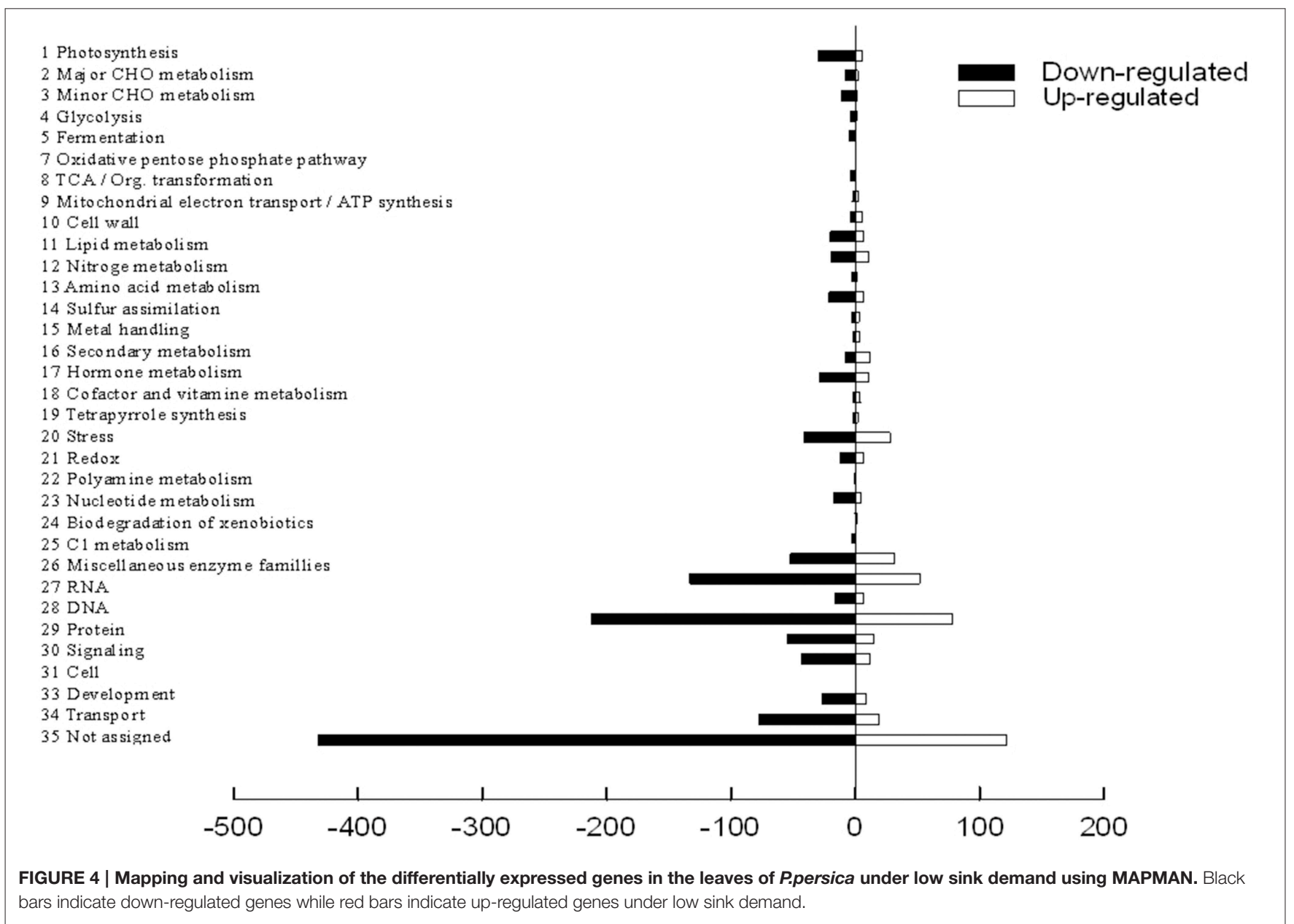


TABLE 2 | The list of genes photosynthesis regulated under low sink demand, based on MapMan functional categories.

\begin{tabular}{|c|c|c|c|c|c|c|}
\hline \multicolumn{2}{|c|}{ Biological process } & \multirow{2}{*}{$\begin{array}{l}\text { Accession number } \\
\text { XP_002298178.1 }\end{array}$} & \multirow{2}{*}{$\begin{array}{c}\text { Fold change } \\
1.27\end{array}$} & \multirow{2}{*}{$\begin{array}{c}\text { Bin } \\
1.1 .1 .1\end{array}$} & \multirow{2}{*}{$\begin{array}{l}\text { Species } \\
\text { Populus trichocarpa }\end{array}$} & \multirow{2}{*}{$\begin{array}{l}\text { Annotation } \\
\text { Light-harvesting complex II protein Lhcb6 }\end{array}$} \\
\hline Light reaction & PSII & & & & & \\
\hline & & AAC34983.1 & 1.09 & 1.1.1.1 & Prunus persica & Light harvesting chlorophyll a/b binding protein \\
\hline & & XP_002510744.1 & -1.05 & 1.1.1.1 & Ricinus communis & Chlorophyll a/b binding protein, Lhcb7 \\
\hline & & XP_002525758.1 & -1.48 & 1.1.1.1 & Ricinus communis & Chlorophyll a/b binding protein, Lhcb3 \\
\hline & & XP_002299309.1 & -1.56 & 1.1.1.1 & Populus trichocarpa & Light-harvesting complex I protein Lhca2 \\
\hline & & NP_565906.1 & -1.23 & 1.1 .1 .2 & Arabidopsis thaliana & PPL2 (psbp-like protein 2); calcium ion binding \\
\hline & & ADB93062.1 & 1.57 & 1.1.1.2 & Jatropha curcas & Chloroplast photosystem II $10 \mathrm{kDa}$ polypeptide \\
\hline & & XP_002526766.1 & -1.97 & 1.1.1.2 & Ricinus communis & $\begin{array}{l}\text { Thylakoid lumenal } 19 \mathrm{kDa} \text { protein, chloroplast } \\
\text { precursor, putative }\end{array}$ \\
\hline & & XP_002521576.1 & -1.71 & 1.1 .1 .2 & Ricinus communis & $\begin{array}{l}\text { Oxygen-evolving enhancer protein } 2 \text {, chloroplast } \\
\text { precursor, putative }\end{array}$ \\
\hline & & XP_002512708.1 & 1.66 & 1.1.1.2 & Ricinus communis & Photosystem II $11 \mathrm{kDa}$ protein precursor, putative \\
\hline & & XP_002515034.1 & -1.39 & 1.1.1.2 & Ricinus communis & $\begin{array}{l}\text { Photosystem II core complex proteins psbY, } \\
\text { chloroplast precursor }\end{array}$ \\
\hline & & NP_196706.2 & -2.49 & 1.1.1.2 & Arabidopsis thaliana & PsbP domain-containing protein 5 \\
\hline & & AAM61552.1 & -1.69 & 1.1.1.2 & Arabidopsis thaliana & Thylakoid lumen protein, chloroplast precursor \\
\hline & & NP_563737.1 & -1.42 & 1.1.1.2 & Arabidopsis thaliana & $\begin{array}{l}\text { Photosystem II D1 precursor processing protein } \\
\text { PSB27-H2 }\end{array}$ \\
\hline & PSI & AAO85557.1 & 1.00 & 1.1.2.2 & Nicotiana attenuata & Photosystem I subunit XI \\
\hline & & BAA07667.1 & -1.27 & 1.1.2.2 & Nicotiana sylvestris & PSI-E subunit of photosystem I \\
\hline & & CAB75430.1 & -1.32 & 1.1.2.2 & Nicotiana tabacum & Putative 16kDa membraneprotein \\
\hline & Redox chain & NP_565711.1 & -1.01 & 1.1 .4 & Arabidopsis thaliana & ATP synthase protein I -related \\
\hline & & XP_002518477.1 & -1.39 & 1.1.4.4 & Ricinus communis & $\begin{array}{l}\text { ATP synthase gamma chain } 2 \text {, chloroplast, } \\
\text { putative }\end{array}$ \\
\hline & & NP_194953.1 & -1.56 & 1.1.4.9 & Arabidopsis thaliana & ATP synthase family \\
\hline & & XP_002516617.1 & -2.63 & 1.1.5.2 & Ricinus communis & Electron carrier, putative \\
\hline & & XP_002533800.1 & -1.03 & 1.1.5.3 & Ricinus communis & Ferredoxin-NADP reductase, putative \\
\hline \multirow{8}{*}{\multicolumn{2}{|c|}{ Calvin cycle }} & ABK76304.1 & -1.47 & 1.3 .9 & Morus alba var. multicaulis & Chloroplast sedoheptulose-1,7-bisphosphatase \\
\hline & & XP_002530415.1 & -1.09 & 1.3 .9 & Ricinus communis & $\begin{array}{l}\text { Sedoheptulose-1,7-bisphosphatase,chloroplast, } \\
\text { putative }\end{array}$ \\
\hline & & ABW38330.1 & -1.18 & 1.3 .7 & Fragaria $X$ ananassa & Chloroplast fructose-1,6-bisphosphatase I \\
\hline & & ABW38331.1 & 1.08 & 1.3 .7 & Fragaria $X$ ananassa & Chloroplast fructose-1,6-bisphosphatase II \\
\hline & & AAR86689.1 & -1.66 & 1.3 .6 & Glycine max & Fructose-bisphosphate aldolase \\
\hline & & XP_002529248.1 & -1.34 & 1.3 .5 & Ricinus communis & Triosephosphate isomerase, putative \\
\hline & & ABA86964.1 & -1.89 & 1.3 .4 & Glycine max & $\begin{array}{l}\text { Glyceraldehyde-3-phosphate dehydrogenase B } \\
\text { subunit }\end{array}$ \\
\hline & & ADD60242.1 & -1.67 & 1.3 .13 & Glycine max & Alpha-form rubisco activase \\
\hline \multicolumn{2}{|c|}{ Photorespiration } & ADD60242.1 & -1.67 & 1.3 .13 & Glycine max & Alpha-form rubisco activase \\
\hline
\end{tabular}

environmental conditions (Boston et al., 1996). HSP70 were accumulated under heat stress (Kosova et al., 2011; Liu et al., 2014). In this study, two members of the HSP70 family were up-regulated (Table 3). Hsp90 is one of the most common of the heat-related proteins. The majority of HSP90 known substrates are signal transduction proteins (Richter and Buchner, 2001), and it also uses a novel protein-folding strategy (Young et al., 2001). A putative HSP90 was up-regulated in P. euphratica at the early stage of heat stress. The -fruit treatment resulted in up-regulating two members of the HSP90 family (Table 3), which should play a role for preventing aggregation and assisting re-folding of non-native proteins. Therefore, we should say the Hsps may have important functions when the sink demand is low in $P$. persica.

Antioxidant enzymes play important roles in scavenging or reducing excessive ROS produced under stress conditions (Lee et al., 2007). Fruit removal remarkably increased the activities of antioxidant enzymes (Duan et al., 2008). However, only the antioxidant enzyme catalase (CAT) was up-regulated in our study. Thioredoxins are proteins that act as antioxidants by catalyzing thiol-disulfide interchange involved in the regulation of the redox environment in cells (Serrato et al., 2002; Gelhaye et al., 2005). Four 
TABLE 3 | The list of genes up-regulated of stress and redox under low sink demand, based on MapMan functional categories.

\begin{tabular}{|c|c|c|c|c|}
\hline Accession number & Fold change & BIN & Species & Annotation \\
\hline \multicolumn{5}{|l|}{ BIOTIC STRESS } \\
\hline ABA26457.1 & 3.70 & 20.10 & Citrullus lanatus & Acidic class III chitinase \\
\hline ACE80957.1 & 3.03 & 20.10 & Prunus dulcis X Prunus persica & Allergen prup 2.01a, putative \\
\hline ADM22305.1 & 2.93 & 20.10 & Prunus domestica & Pathogenesis related protein 5 \\
\hline ACZ52964.1 & 2.21 & 20.10 & Dimocarpus longan & Chitinase \\
\hline ACM45716.1 & 1.31 & 20.10 & Pyrus pyrifolia & Class IV chitinase \\
\hline AAK82460.1 & 1.30 & 20.10 & Cinnamomum camphora & Type 2 ribosome-inactivating protein cinnamomin III precursor \\
\hline AAR28754.1 & 1.25 & 20.10 & Solanum lycopersicum & Bax inhibitor \\
\hline ACM45716.1 & 1.12 & 20.10 & Pyrus pyrifolia & Class IV chitinase \\
\hline ABC47922.1 & 1.07 & 20.10 & Malus X Domestica & Pathogenesis-related protein 1a \\
\hline XP_002519358.1 & 1.56 & 20.1 .7 & Ricinus communis & Leucine-rich repeat-containing protein, putative \\
\hline \multicolumn{5}{|l|}{ ABIOTIC STRESS } \\
\hline XP_002285199.1 & 2.10 & 20.20 & Vitis vinifera & Spx domain-containing protein 2 isoform 1 \\
\hline XP_002318460.1 & 3.23 & 20.2 .1 & Populus trichocarpa & Heat shock 22k family protein \\
\hline XP_006486450.1 & 3.18 & 20.2 .1 & Citrus sinensis & 18.2 kDa class I heat shock protein-like \\
\hline P30236.1 & 2.49 & 20.2 .1 & Glycine max & $22.0 \mathrm{kDa}$ class iv heat shock protein \\
\hline NP_200076.1 & 1.94 & 20.2 .1 & Arabidopsis thaliana & Heat shock protein 90.1 \\
\hline EOX91407.1 & 1.82 & 20.2 .1 & Theobroma cacao & Heat shock factor 4 \\
\hline XP_002332067.1 & 1.72 & 20.2 .1 & Populus trichocarpa & Heat shock protein 70 cognate \\
\hline CAA52149.1 & 1.28 & 20.2 .1 & Cucumis sativus & Heat shock protein 70 \\
\hline XP_004306709.1 & 1.26 & 20.2 .1 & Fragaria vesca subsp. vesca & Bag family molecular chaperone regulator 6-like \\
\hline XP_002515568.1 & 1.19 & 20.2 .1 & Ricinus communis & Heat shock protein binding protein, putative \\
\hline XP_002879575.1 & 1.18 & 20.2 .1 & Arabidopsis lyrata subsp. lyrata & DNAJ/Hsp40 heat shock N-terminal domain-containing protein \\
\hline NP_178487.1 & 1.01 & 20.2 .1 & Arabidopsis thaliana & Heat shock protein 90 \\
\hline ADN33944.1 & 1.15 & 20.2 .2 & Cucumis melo subsp. melo & Cold-shock DNA-binding family protein \\
\hline ADP30960.1 & 1.60 & 20.2 .3 & Gossypium hirsutum & Dehydration-induced 19-like protein \\
\hline XP_002535200.1 & 1.93 & 20.2 .99 & Ricinus communis & Major latex protein, putative \\
\hline XP_002864359.1 & 1.26 & 20.2 .99 & Arabidopsis lyrata subsp. lyrata & Pollen ole e 1 allergen and extensin family protein \\
\hline ABD33344.1 & 1.18 & 20.2 .99 & Medicago truncatula & Pollen ole e 1 allergen and extensin \\
\hline NP_850016.1 & 1.03 & 20.2 .99 & Arabidopsis thaliana & $\mathrm{Rd} 2$ \\
\hline \multicolumn{5}{|l|}{ REDOX } \\
\hline AAD33596.1 & 1.77 & 21.10 & Hevea brasiliensis & Thioredoxin $\mathrm{H}$ \\
\hline XP_003517423.1 & 1.45 & 21.10 & Glycine max & Thioredoxin-like 2, Chloroplastic-Like \\
\hline СAH59452.1 & 1.44 & 21.10 & Plantago major & Thioredoxin 3 \\
\hline NP_196046.2 & 1.06 & 21.10 & Arabidopsis thaliana & WCRKC2 (WCRKC thioredoxin 2) \\
\hline XP_002878810.1 & 1.57 & 21.20 & Arabidopsis lyrata subsp. lyrata & Membrane-associated progesterone binding protein 2 \\
\hline XP_002869447.1 & 1.05 & 21.2 .2 & Arabidopsis lyrata subsp. lyrata & Gamma-glutamyl transpeptidase 3 \\
\hline CAD42908.1 & 2.41 & 21.60 & Prunus persica & Catalase \\
\hline
\end{tabular}

thioredoxins (thioredoxin $\mathrm{h}$, thioredoxin 3, thioredoxin 2, and thioredoxin 3-2) were up-regulated in our study (Table 3) suggesting that CAT and thioredoxin play an important role in maintaining redox homeostasis in $P$. persica cells under low sink demand.

\section{CONCLUSION}

This study provided a global picture of gene changes in peach leaves under low sink demand using the Solexa digital gene expression system. Under low sink demand condition, net photosynthesis rate may be reduced due to increased leaf temperature, during which some genes related to the electron transport chain of photosynthesis and HSPs were differentially regulated. It helped to gain insight into how peach leave photosynthesis adapted to low demand.

\section{AUTHOR CONTRIBUTIONS}

WD performed the experiments and wrote the manuscript. HX and GL helped perform the experiments and data analysis. ZL and PF helped design the experiment. SL designed the experiment and reviewed the manuscript. All authors have read and approved the final manuscript. 


\section{FUNDING}

This work is supported by the National Natural Science Foundation of China (No. 30800743 and 31071758).

\section{SUPPLEMENTARY MATERIAL}

The Supplementary Material for this article can be found online at: http://journal.frontiersin.org/article/10.3389/fpls.2016. 00883

\section{REFERENCES}

Audic, S., and Claverie, J. M. (1997). The significance of digital gene expression profiles. Genome Res. 7, 986-995.

Basu, P. S., Sharma, A., Garg, I. D., and Sukumaran, N. P. (1999). Tuber sink modifies photosynthetic response in potato under water stress. Environ. Exp. Bot. 42, 25-39. doi: 10.1016/S0098-8472(99)00017-9

Benjamini, Y., Drai, D., Elmer, G., Kafkafi, N., and Golani, I. (2001). Controlling the false discovery rate in behavior genetics research. Behav. Brain Res. 125, 279-284. doi: 10.1016/S0166-4328(01)00297-2

Berry, J., and Bjôrkman, O. (1980). Photosynthetic response and adaptation to temperature in higher plants. Annu. Rev. Plant Physiol. 31, 491-543. doi: 10.1146/annurev.pp.31.060180.002423

Boston, R. S., Viitanen, P. V., and Vierling, E. (1996). Molecular chaperones and protein folding in plants. Plant Mol. Biol. 32, 191-222. doi: 10.1007/BF00039383

Buwalda, J. G., and Smith, G. S. (1990). Effects of partial defoliation at various stages of the growing season on fruit yields, root growth and return bloom of kiwifruit vines. Sci. Hortic. 42, 29-44. doi: 10.1016/0304-4238(90)9 0145-5

Cheng, J. S., Fan, P. G., Liang, Z. C., Wang, Y. Q., Niu, N., Li, W. D., et al. (2009). Accumulation of end products in source leaves affects photosynthetic rate in peach via alteration of stomatal conductance and photosynthetic efficiency. J. Am. Soc. Hortic. Sci. 134, 667-676.

Cheng, S. H., Moore, B., and Seemann, J. R. (1998). Effects of short- and long-term elevated $\mathrm{CO}_{2}$ on the expression of Ribulose-1,5-bisphosphate carboxylase/oxygenase genes and carbohydrate accumulation in leaves of Arabidopsis thaliana (L.) Heynh. Plant Physiol. 116, 715-723. doi: 10.1104/pp.116.2.715

DaMatta, F. M., Cunha, R. L., Antunes, W. C., Martins, S. C., Araujo, W. L., Fernie, A. R., et al. (2008). In field-grown coffee trees sourcesink manipulation alters photosynthetic rates, independently of carbon metabolism, via alterations in stomatal function. New Phytol. 178, 348-357. doi: 10.1111/j.1469-8137.2008.02367.x

De Souza, A. P., Gaspar, M., Da Silva, E. A., Ulian, E. C., Waclawovsky, A. J., Nishiyama-Jr, M. Y., et al. (2008). Elevated $\mathrm{CO}_{2}$ increases photosynthesis, biomass and productivity, and modifies gene expression in sugarcane. Plant Cell Environ. 31, 1116-1127. doi: 10.1111/j.1365-3040.2008.01822.x

Downton, W. J. S., Grant, W. J. R., and Loveys, B. R. (1987). Diurnal changes in the photosynthesis of field-grown grape vines. New Phytol. 105, 71-80. doi: 10.1111/j.1469-8137.1987.tb00111.x

Duan, W., Fan, P. G., Wang, L. J., Li, W. D., Yan, S. T., and Li, S. H. (2008). Photosynthetic response to low sink demand after fruit removal in relation to photoinhibition and photoprotection in peach trees. Tree Physiol. 28, 123-132. doi: 10.1093/treephys/28.1.123

Fan, P. G., Li, L. S., Duan, W., Li, W. D., and Li, S. H. (2010). Photosynthesis of young apple trees in response to low sink demand under different air temperatures. Tree Physiol. 30, 313-325. doi: 10.1093/treephys/tpp114

Farquhar, G. D., and Sharkey, T. D. (1982). Stomatal conductance and photosynthesis. Annu. Rev. Plant Physiol. 33, 317-345. doi: 10.1146/annurev. pp.33.060182.001533
Figure S1 | Sequencing saturation analysis of peach leaf libraries under normal sink demand (+fruit) or low sink demand (-fruit).

Table S1 | Summary of parameters, formulae and their description using data extracted from chlorophyll a fluorescence transient (O-J-I-P-test).

Table S2 | List of primers used for the Real-time PCR.

Table S3 | Detail information of peach DEGs under low sink demand.

Table S4 | Alignment of the unique tags to the reference genome and annotated genes from peach leaves under normal sink demand (+fruit) or low sink demand (-fruit) peach trees.

Table S5 | List of genes selected for Real-time PCR.

Gelhaye, E., Rouhier, N., Navrot, N., and Jacquot, J. P. (2005). The plant thioredoxin system. Cell Mol. Life Sci. 62, 24-35. doi: 10.1007/s00018-0044296-4

Gucci, R., Corelli, G., Tustin, S., and Ravaglia, G. (1995). The effect of defruiting at different stages of fruit development on leave photosynthsis of Golden Delicious apple. Tree Physiol. 15, 35-40.

AC’t Hoen, P., Ariyurek, Y., Thygesen, H. H., Vreugdenhil, E., Vossen, R. H., de Menezes, R. X., et al. (2008). Deep sequencing-based expression analysis shows major advances in robustness, resolution and inter-lab portability over five microarray platforms. Nucleic. Acids Res. 36, e141. doi: 10.1093/nar/gkn705

Iglesias, D. J., Lliso, I., Tadeo, F. R., and Talon, M. (2002). Regulation of photosynthesis through source: sink imbalance in citrus is mediated by carbohydrate content in leaves. Physiol. Plant 116, 563-572. doi: 10.1034/j.1399-3054.2002.1160416.x

Ishihara, S., Takabayashi, A., Ido, K., Endo, T., Ifuku, K., and Sato, F. (2007). Distinct functions for the two PsbP-like proteins PPL1 and PPL2 in the chloroplast thylakoid lumen of Arabidopsis. Plant Physiol. 145, 668-679. doi: 10.1104/pp.107.105866

Kawakami, K., Iwai, M., Ikeuchi, M., Kamiya, N., and Shen, J. R. (2007). Location of PsbY in oxygen-evolving photosystem II revealed by mutagenesis and X-ray crystallography. FEBS Lett. 581, 4983-4987. doi: 10.1016/j.febslet.2007.09.036

Kosoví, K., Vítámvás, P., Prášil, I. T., and Renaut, J. (2011). Plant proteome changes under abiotic stress - Contribution of proteomics studies to understanding plant stress response. J. Proteomics. 74, 1301-1322. doi: 10.1016/j.jprot.2011.02.006

Lee, D. G., Ahsan, N., Lee, S. H., Kang, K. Y., Bahk, J. D., Lee, I. J., et al. (2007). A proteomic approach in analyzing heat-responsive proteins in rice leaves. Proteomics 7, 3369-3383. doi: 10.1002/pmic.200700266

Lee, J. M., Sathish, P., Donaghy, D. J., and Roche, J. R. (2011). Impact of defoliation severity on photosynthesis, carbon metabolism and transport gene expression in perennial ryegrass. Funct. Plant Biol. 38, 808-817. doi: 10.1071/FP11048

Li, S. H. M., Génard, C., Bussi, J. G., Huguet, R., Habib, J., et al. (2001). Fruit quality and leaf photosynthesis in response to microenvironment modification around individual fruit by covering the fruit with plastic in nectarine and peach trees. J. Hortic. Sci. Biotech. 76, 61-69. doi: 10.1080/14620316.2001.11511328

Li, S. H., Zhang, X. P., Meng, Z. Q., and Wang, X. (1994). Responses of peach trees to modified pruning. I. vegetative growth. N. Zeal. J. Crop Hortic. Sci. 22, 401-409. doi: 10.1080/01140671.1994.9513852

Li, W. D., Duan, W., Fan, F. G., Yan, S. T., and Li, S. H. (2007). Photosynthesis in response to sink-source activity in relation to the end products and metabolic enzymes in peach trees. Tree Physiol. 27, 1307-1318. doi: 10.1093/treephys/27.9.1307

Li, W. D., Li, S. H., Yang, S. H., Yang, J. M., Zheng, X. B., Li, X. D., et al. (2005). Photosynthesis in response to sink-source manipulation during different phenological stages of fruit development in peach trees: regulation by stomatal aperture and leaf temperature. J. Hortic. Sci. Biotechnol. 80, 481-487. doi: $10.1080 / 14620316.2005 .11511964$

Liu, G. T., Ma, L., Duan, W., Wang, B. C., Li, J. H., Xu, H. G., et al. (2014). Differential proteomic analysis of grapevine leaves by iTRAQ reveals responses to heat stress and subsequent recovery. BMC Plant Biol. 14:110. doi: $10.1186 / 1471-2229-14-110$ 
López, R., Brossa, R., Gil, L., and Pita, P. (2015). Stem girdling evidences a trade-off between cambial activity and sprouting and dramatically reduces plant transpiration due to feedback inhibition of photosynthesis and hormone signaling. Front. Plant Sci. 6:285. doi: 10.3389/fpls.2015. 00285

Luo, H. B., Ma, L., Xi, H. F., Duan, W., Li, S. H., Loescher, W., et al. (2011). Photosynthetic responses to heat treatments at different temperatures and following recovery in grapevine (Vitis amurensis L.) leaves. PLoS ONE 6:e23033. doi: 10.1371 /journal.pone.0023033

McCormick, A. J., Cramer, M. D., and Watt, D. A. (2008). Changes in photosynthetic rates and gene expression of leaves during a source-sink perturbation in sugarcane. Ann. Bot. 101, 89-102. doi: 10.1093/aob/mcm258

Morrissy, A. S., Morin, R. D., Delaney, A., Zeng, T., McDonald, H., Jones, S., et al. (2009). Next-generation tag sequencing for cancer gene expression profiling. Genome Res. 19, 1825-1835. doi: 10.1101/gr.094482.109

Palmblad, M., Mills, D. J., and Bindschedler, L. V. (2008). Heat-shock response in Arabidopsis thaliana explored by multiplexed quantitative proteomics using differential metabolic labeling. J. Proteome Res. 7, 780-785. doi: $10.1021 /$ pro705340

Paul, M. J., and Foyer, C. (2001). Sink regulation of photosynthesis. J. Exp. Bot. 52, 1383-1400. doi: $10.1093 /$ jexbot/52.360.1383

Richter, K., and Buchner, J. (2001). Hsp90: chaperoning signal transduction. J. Cell Physiol. 188, 281-290. doi: 10.1002/jcp.1131

Roose, J. L., Wegener, K. M., and Pakrasi, H. B. (2007). The extrinsic proteins of Photosystem II. Photosynth. Res. 92, 369-387. doi: 10.1007/s11120-006-9117-1

Serrato, A. J., Pérez-Ruiz, J. M., and Cejudo, F. J. (2002). Cloning of thioredoxin $h$ reductase and characterization of the thioredoxin reductase-thioredoxin $h$ system from wheat. Biochem. J. 367, 491-497. doi: 10.1042/bj20020103

Setter, T. L., Btun, W. A., and Brenner, M. L. (1980). Stomatal closure and photosynthetic inhibition in soybean leaves induced by petiole girdling and pod removal. Plant Physiol. 6, 884-887. doi: 10.1104/pp.65.5.884

Standfuss, J., and Kühlbrandt, W. J. (2004). The three isoforms of the light-harvesting complex II: spectroscopic feature, trimer formation, and functional roles. J. Biol. Chem. 279, 36884-36891. doi: 10.1074/jbc.M402 348200

Strasser, B. J. (1997). Donor side capacity of Photosystem II probed by chlorophyll a fluorescence transients. Photosynth. Res. 52, 147-155. doi: 10.1023/A:1005896029778

Tong, Z., Gao, Z., Wang, F., Zhou, J., and Zhang, Z. (2009). Selection of reliable reference genes for gene expression studies in peach using real-time PCR. $B M C$ Mol. Biol. 10:71. doi: 10.1186/1471-2199-10-71

Turner, G., Yu, O., and Subramanian, S. (2012). Genome organization and characteristics of soybean microRNAs. BMC Genomics 13:169. doi: 10.1186/1471-2164-13-169
Usadel, B., Poree, F., Nagel, A., Lohse, M., Czedik-Eysenberg, A., and Stitt, M. (2009). A guide to using MapMan to visualize and compare Omics data in plants: a case study in the crop species, Maize. Plant Cell Environ. 32, 1211-1229. doi: 10.1111/j.1365-3040.2009.01978.x

Walker, A. J., and Ho, L. C. (1977). Carbon translocation in the tomato: carbon import and fruit growth. Ann. Bot. 41, 813-823.

Wu, B. H., Huang, H. Q., Fan, P. G., Liu, G. J., and Li, S. H. (2008). Photosynthetic responses to sink-source manipulation in five peach cultivars varying in maturity date. J. Am. Soc. Hortic. Sci. 133, 278-283.

Wu, J., Zhang, Y., Zhang, H., Huang, H., Folta, K. M., and Lu, J. (2010). Whole genome wide expression profiles of Vitis amurensis grape responding to downy mildew by using Solexa sequencing technology. BMC Plant Biol. 10:234. doi: 10.1186/1471-2229-10-234

Xiang, M., Chen, S., Wang, L., Dong, Z., Huang, J., Zhang, Y., et al. (2013). Effect of vulculic acid produced by Nimbya alternantherae on the photosynthetic apparatus of Alternanthera philoxeroides. Plant Physiol. Biochem. 65, 81-88. doi: 10.1016/j.plaphy.2013.01.013

Yamaguchi-Shinozaki, K., Kasuga, M., Liu, Q., Nakashima, K., Sakuma, Y., Abe, H. et al. (2002). Biological mechanisms of drought stress response. JIRCAS Work Rep. 23, 1-8.

Yan, B. F., Duan, W., Liu, G. T., Xu, H. G., Wang, L. J., and Li, S. H. (2013). Response of bean (Vicia faba L.) plants to low sink demand by measuring the gas exchange rates and chlorophyll a fluorescence kinetics. PLOS ONE 8:e80770. doi: 10.1371/journal.pone.0080770

Yan, S. T., Li, X. D., Li, W. D., Fan, P. G., Duan, W., and Li, S. H. (2011). Photosynthesis and chlorophyll fluorescence response to low sink demand of tubers and roots in Dahlia pinnata source leaves. Biol. Plantarum 55, 83-89. doi: 10.1007/s10535-011-0011-0

Young, J. C., Moarefi, I., and Hartl, F. U. (2001). Hsp90: a specialized but essential proteinfolding tool. J. Cell Biol. 154, 267-274. doi: 10.1007/s10535-011-0011-0

Zhou, R., and Quebedeaux, B. (2003). Changes in photosynthesis and carbohydrate metabolism in mature apple leaves in response to whole plant source-sink manipulation. J. Am. Soc. Hortic. Sci. 128, 113-119.

Conflict of Interest Statement: The authors declare that the research was conducted in the absence of any commercial or financial relationships that could be construed as a potential conflict of interest.

Copyright $\odot 2016$ Duan, Xu, Liu, Fan, Liang and Li. This is an open-access article distributed under the terms of the Creative Commons Attribution License (CC BY). The use, distribution or reproduction in other forums is permitted, provided the original author(s) or licensor are credited and that the original publication in this journal is cited, in accordance with accepted academic practice. No use, distribution or reproduction is permitted which does not comply with these terms. 